\title{
Comparison of Different Methods of Residual Stress Determination of Cold-Rolled Austenitic-Ferritic, Austenitic and Ferritic Steels
}

\author{
ČAPEK Jiři ${ }^{1, a,{ }^{*}}$, TROJAN Karel $^{1, b}$, NĚMEČEK Jakub ${ }^{1, c}$, GANEV Nikolaj ${ }^{1, \mathrm{~d}}$ and \\ KOLAŘÍK Kamil ${ }^{1, \mathrm{e}}$
}

${ }^{1}$ Department of Solid State Engineering, Faculty of Nuclear Sciences and Physical Engineering, Czech Technical University in Prague, Trojanova 13, 12000 Prague 2, Czech Republic

ajiri.capek@fjfi.cvut.cz, bkarel.trojan@fjfi.cvut.cz, ${ }^{c}$ jakub.nemecek@fjfi.cvut.cz, dnikolaj.ganev@fjfi.cvut.cz, ${ }^{\mathrm{e}}$ kamil.kolarik@fjfi.cvut.cz

\section{Keywords: X-Ray Diffraction, Residual Stresses, Cold-Rolling, Texture}

\begin{abstract}
The aim of this contribution was to compare four methods of residual stresses determination of single-phase and dual-phase steels after cold-rolling primarily using X-ray diffraction techniques. Firstly, without taking into account the preferred orientation ( $\sin ^{2} \psi$ method), secondly from the geometry of four-point bending, thirdly without neglecting the texture (harmonic function method). And mainly, the new method, by calculating anisotropic elastic constants as a weighted average between single-crystal and X-ray elastic constants with weighting being done according to the relative intensities in the measured directions. The applicability of the new method of residual stresses determination in textured materials was proofed; however, the method needs further verification.
\end{abstract}

\section{Introduction}

The majority of practically used diffraction measurements methods and algorithms for residual stresses (RS) calculation assume the case of isotropic (non-textured) polycrystalline material. Due to the comparatively frequent existence of the preferred orientation (texture), it is more than desirable to have at disposal a method, procedure and even a computation algorithm for proper and correct RS determination. Currently, a universal method with the potential to properly evaluate RS in textured materials is, unfortunately, still missing and this issue is tackled either, in the worst scenario, by neglecting the texture (X-ray elastic constants (XEC) are used) or by choosing one of the usually proposed methods (i.e. calculation of anisotropic elastic constants (X-ray stress factors - XSF), e.g. harmonic function [1], crystallite group [2], strain pole figures [3] methods etc.).

For this purpose, a new method was developed and used for determination of residual stresses without neglecting texture. The new method is based on the Dölle model $[4,5]$. However, contrary to Dölle method, this method determines the XSF $\left(R_{i j}\right)$ as the weighted average between the single-crystal elastic constants $\left(s_{33 i j}\right)$ and the XEC $\left(r_{i j}\right)$ where weighing is performed according to the relative intensities $I$ in the measured directions $\varphi$, $\psi$, see Eq. 1 .

$$
R_{i j}(h k l, \varphi, \psi)=I(h k l, \varphi, \psi) r_{i j}(h k l)+(1-I(h k l, \varphi, \psi)) s_{33 i j},
$$

where $h k l$ are the Miller indices of the analysed planes. For texture limits, i.e. $I=0$ and $I=1$, the applicability and correctness of the method is automatically proofed. The general method uses function $f(I)$, which depends on the texture. To simplify and according to previous experiments, the function $f(I)$ could be approximated by a quadratic function (there is linear function in Eq. 1). Instead of other methods, this method allows to determine RS in materials with a very weak, 
strong and moderate texture too. The main disadvantage of this method results from the accuracy of orientation distribution function (ODF) calculation, it is the same case as for the harmonic function method.

\section{Experiment}

The tested samples of plate shape were made of AISI 420 (ferritic), AISI 304 (austenitic) and AISI 318LN (austenitic-ferritic or duplex) type of stainless steel. The samples were cold-rolled to a thickness of $1.5 \mathrm{~mm}$ with $0,10,20,30,40$, and 50\% reduction in thickness (deformation). Before deformation, the austenitic and ferritic with duplex samples were annealed in air laboratory furnace for 4 hours at $840^{\circ} \mathrm{C}$ and 7 hours at $650^{\circ} \mathrm{C}$, respectively, in order to reduce residual stresses. According to the type of steel and thickness reduction, the tested samples were marked as F0-F50, A0-A50, D0-D50, and $\mathrm{D}_{\mathrm{F}} 0-\mathrm{D}_{\mathrm{F}} 50$ and $\mathrm{D}_{\mathrm{A}} 0-\mathrm{D}_{\mathrm{A}} 50$ for particular phases of duplex steel.

The CoK $\alpha$ radiation and the $X$ 'Pert $P R O M P D$ diffractometer were used to texture and phase analyses. Texture analysis was performed on the basis of the ODF calculated from experimental pole figures $(\mathrm{PF})$, which were obtained from three diffraction lines $\{110\},\{200\},\{211\}$ of ferrite phase $(\alpha-\mathrm{Fe})$ and $\{111\},\{200\},\{220\}$ of austenite phase $(\gamma$-Fe) using MTEX software [6]. Due to overlapping of diffraction lines $\{110\}_{\alpha}$ and $\{111\}_{\gamma}$ in duplex steel, $\{220\}_{\alpha}$ and $\{311\}_{\gamma}$ were analysed instead of them. The ResMat software was used to determine the harmonic coefficients, which are necessary for XSF calculation using harmonic function method.

The $X^{\prime}$ Pert PRO MPD diffractometer with manganese and chromium radiation was used to measure lattice deformations in austenite and ferrite phases, respectively, in the rolling direction. The diffraction angles $2 \theta^{h k l}$ were determined from the peaks of the diffraction lines $K \alpha_{1}$ of planes $\{311\}$ of the austenite and $\{211\}$ of the ferrite phase. The diffraction lines $K \alpha_{1}$ were fitted by the Pearson VII function and the Rachinger's method was used for separation of the diffraction lines $K \alpha_{1}$ and $K \alpha_{2}$. The XEC were obtained in accordance with the Hill model [7] from single-crystal elastic constants, see Tab. 1. The Winholtz \& Cohen method [2] was used for calculation of RS from lattice deformations.

Tab. 1 Single-crystal elastic constants of ferrite and austenite [8]

\begin{tabular}{|c|c|c|c|}
\hline phase & $\mathbf{C}_{\mathbf{1 1}}, \mathbf{G P a}$ & $\mathbf{C}_{\mathbf{1 2}}, \mathbf{G P a}$ & $\mathbf{C}_{\mathbf{4 4}}, \mathbf{G P a}$ \\
\hline ferrite & 231 & 134 & 116 \\
\hline austenite & 198 & 125 & 122 \\
\hline
\end{tabular}

\section{Results and discussions}

The phase compositions of the tested samples are shown in Tab. 2 and Fig. 1. In the ferritic samples, only the ferrite phase was observed. Due to stronger plastic deformation, increasing amount of strain-induced martensite $\left(\alpha^{\prime}\right)$ was found in the austenitic samples with higher deformation. The two phases based on chromium $\left(\mathrm{Cr}_{23} \mathrm{C}_{6}+\mathrm{FeCr}\right)$ were analysed in duplex samples. The trends from Fig. 1 result from the combination of strong plastic deformation ( $\gamma \rightarrow \alpha^{\prime}$ ) with annealing ( $\alpha \rightarrow \gamma+\mathrm{Cr}_{23} \mathrm{C}_{6}+\mathrm{FeCr}$ ) [9]. For these reasons, the amount of austenite phase is decreasing, the ferrite phase is constant and the chromium phases is increasing with higher deformation.

The presented stresses $\sigma$ (measured by X-ray diffraction) are superposition of the external stresses $\sigma_{N}$ generated by the four-point bending, and the RS of surfaces areas of the tested samples after annealing $\sigma_{R S}$, i.e. $\sigma=\sigma_{N}+\sigma_{R S}$. For the external stresses calculation, Young's modules of tested materials were measured using the ultrasonic pulse-echo method [10]. Values of $\sigma^{\prime}{ }_{N}$ represent the theoretical values of the measured/experimental value of $\sigma$. In ideal case, the values of $\sigma$ should be equal to $\sigma^{\prime}{ }_{N}$. 
The determined stresses $\sigma$ relevant for the surface layers depending on external stresses can be seen in Figs. 2. Stresses calculated using common $\sin ^{2} \psi$ method differ from $\sigma{ }_{N}$ values due to omitting of presence of texture, i.e. without taking into account the potential non-linear regression of $d\left(\sin ^{2} \psi\right)$, and using the XEC instead of the XSF.

Tab. 2 Phase compositions in wt.\% of austenitic samples

\begin{tabular}{|c|c|c|}
\hline sample & $\begin{array}{c}\text { strain-induced } \\
\text { martensite }\end{array}$ & austenite \\
\hline A0 & 2.0 & 98.0 \\
\hline A10 & 1.7 & 98.3 \\
\hline A20 & 3.2 & 96.8 \\
\hline A30 & 2.5 & 97.5 \\
\hline A40 & 4.7 & 95.3 \\
\hline A50 & 4.2 & 95.8 \\
\hline
\end{tabular}

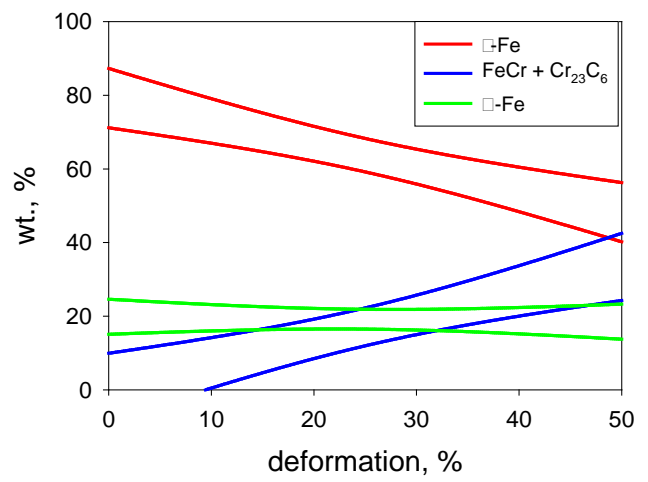

Fig. 1 Phase compositions of duplex samples with 95\% confidence interval

The stresses determined by the harmonic function method have in the most cases higher values and errors in comparison with other methods. The main reason is presence of a sharp texture, see Fig. 3 and [11], which the harmonic functions are not able to describe correctly. Secondly, this method strongly depends on the accuracy of harmonic coefficients derived from calculation of ODF, which is closely related to microstructure, mainly grain size.

The new developed method uses relative intensities of pole figures of the given $\{h k l\}$ diffraction planes. In this method, the PF or ODF are not fitted by any functions, so it is suitable for materials with very strong and sharp textures. Nevertheless, same as for the harmonic function method, the accuracy strongly depends on the ODF calculation and quality of measured data. This is the main reason, why the values of stresses determined by the new method are not equal to the $\sigma^{\prime}{ }_{N}$ values. The good validity of the proposed method is for one-phase steel, where the function $f(I)$ could be approximated by a quadratic function, see Figs. 2a and $2 \mathrm{~b}$. Due to the multi-phase interaction during deformation of austenitic and duplex samples, the accuracy of the method was confirmed for stresses up to $50 \%$ of yield strength, see Figs. 2c-h. The influence of multi-phase interaction is not a part of the proposed method, that is the reason why the validity for higher deformation was not proofed. For all cases, the RS values were determined by the proposal method with smaller experimental errors than other methods. 


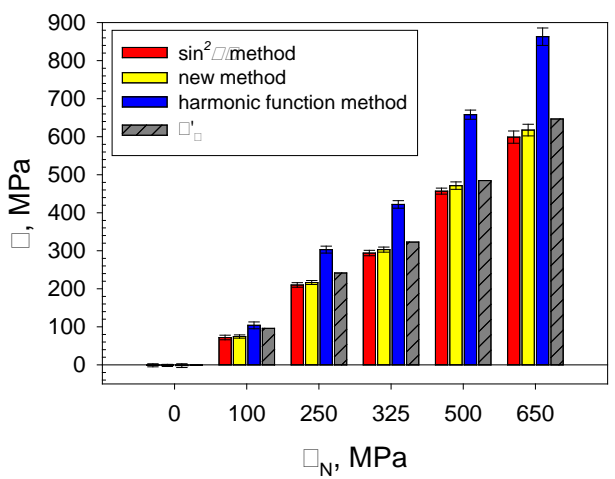

a) Sample F0

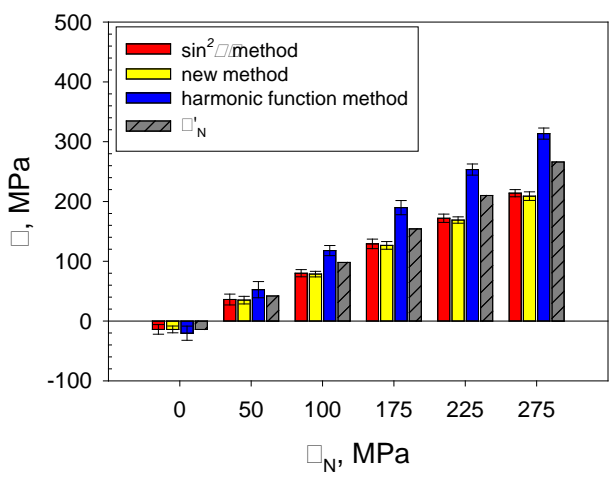

c) Sample A0

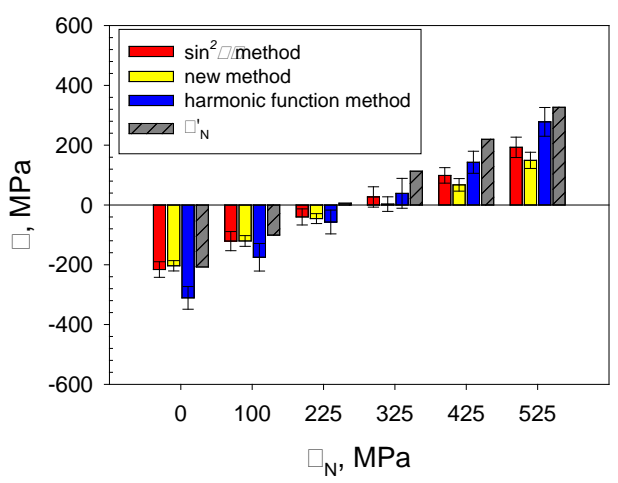

e) Sample $\mathrm{D}_{\mathrm{F}} \mathrm{O}$

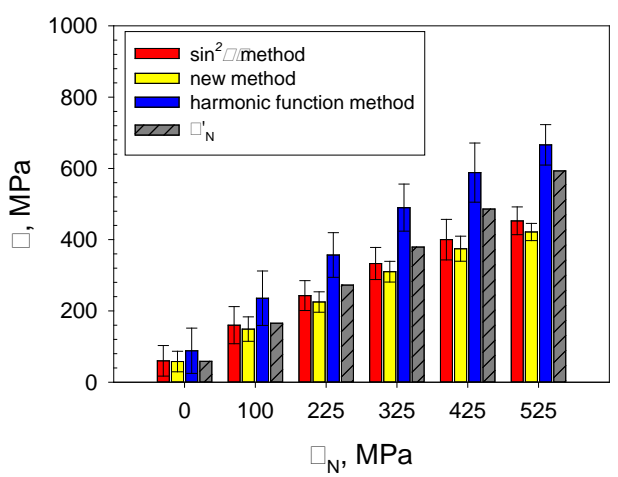

g) Sample $\mathrm{D}_{\mathrm{A}} 0$

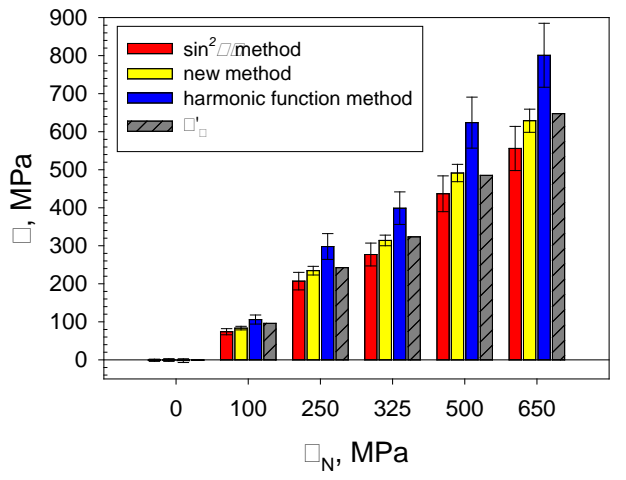

b) Sample F50

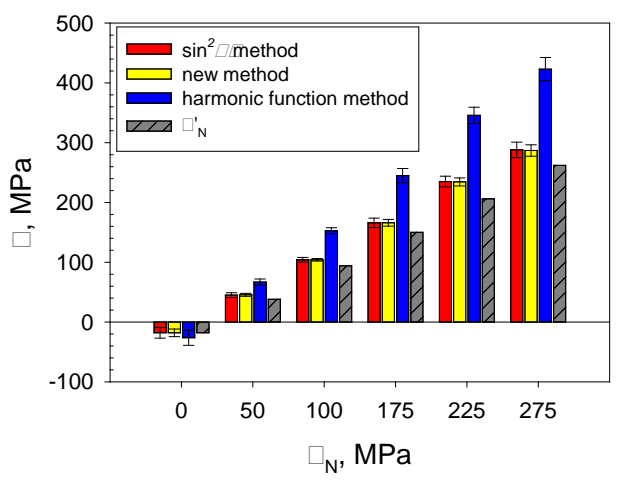

d) Sample A50

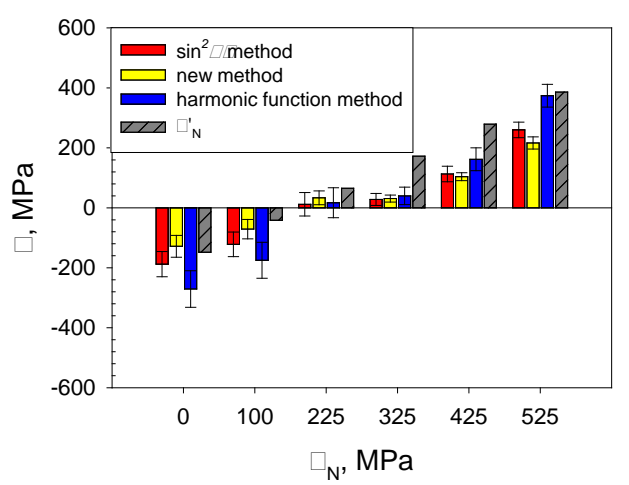

f) Sample $D_{F} 50$

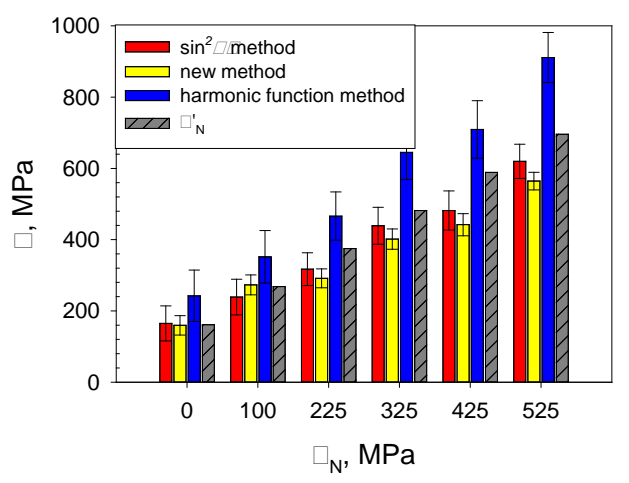

h) Sample $\mathrm{D}_{\mathrm{A}} 50$

Fig. 2 Determined stresses $\sigma$ depending on $\sigma^{\prime}{ }_{N}$ stress with 0 and $50 \%$ deformation 

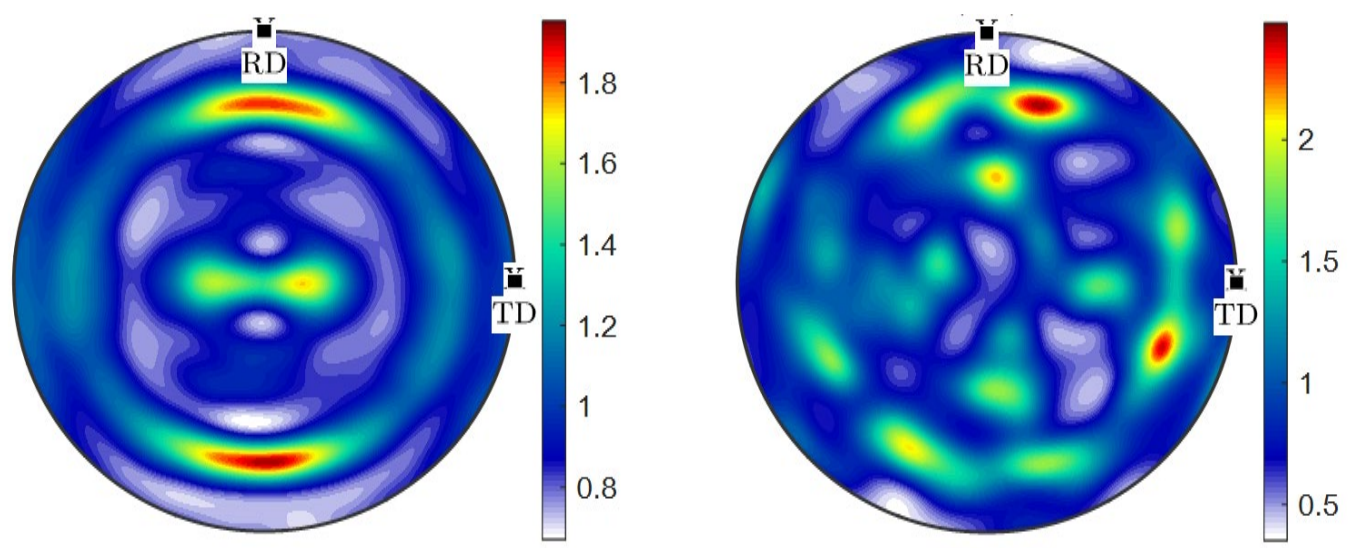

Fig. 3 Example of PF of $\{211\}$ planes with sharp texture of $F 50$ and $D_{F} 50$ samples

After the final annealing, the residual stresses $\sigma_{R S}$ should be approx. equal to zero. This statement is not fulfilled for the duplex samples. If the RS of each phase of duplex steel are added up, with taking into account the wt.\%, the result is not zero. The possible reason is the presence of chromium phases with non-zero residual stresses.

\section{Conclusions}

The applicability of the new method of residual stress determination in textured materials was proofed for single-phase materials and for major phases of multi-phase materials up to approx. $50 \%$ yield strength, see Figs. 2. However, comparing with the standard $\sin ^{2} \psi$ and harmonic function methods, much more accurate results were achieved. The main reason is the presence of very sharp texture, especially in duplex steel. Other reasons are using different methods of calculation RS and mainly accuracy of ODF calculation.

\section{Acknowledgement}

This work was supported by the Czech Science Foundation, grant No. 14-36566G.

\section{References}

[1] H.J. Bunge, Texture Analysis in Materials Science, Butterworth, London, 1982.

[2] U. Welzel, et al. Stress analysis of polycrystalline thin films and surface regions by X-ray diffraction, J. Appl. Crystallogr. 38 (2005) 1-29. https://doi.org/10.1107/S0021889804029516

[3] C.M. Brakman, A general treatment of X-ray (residual) macro-stress determination in textured cubic materials: General expressions, cubic invariancy and application to X-ray strain pole figures, Cryst. Res. Technol. 20.5 (1985) 593-618. https://doi.org/10.1002/crat.2170200503

[4] H. Dölle, The Influence of Multiaxial Stress States, Stress Gradients and Elastic Anisotropy on the Evaluation of (Residual) Stresses by X-rays, J. Appl. Cryst. 12 (1979) 489-501. https://doi.org/10.1107/S0021889879013169

[5] J. Capek, Z. Pala, O. Kovarik, Residual stresses determination in textured substrates for plasma sprayed coatings, IOP Conf. Ser.: Mater. Sci. Eng. 82.1 (2015) 012112.

[6] F. Bachmann, R. Hielscher, H. Schaeben, Texture Analysis with MTEX | Free and Open Source Software Toolbox, Solid State Phenomen. 60 (2010) 63-68. https://doi.org/10.4028/www.scientific.net/SSP.160.63 
[7] J.D. Eshelby, The determination of the elastic field of an ellipsoidal inclusion, and related problems, Proc. R. Soc. Lond. A. 241.1226 (1957) 376-396.

https://doi.org/10.1098/rspa.1957.0133

[8] R. Dakhlaoui, C. Braham, A. Baczmański, Mechanical properties of phases in austenoferritic duplex stainless steel - Surface stresses studied by X-ray diffraction, Mater. Sci. Eng.: A. 444 (2007) 6-17. https://doi.org/10.1016/j.msea.2006.06.074

[9] I. Alvarez-Armas, Duplex Stainless Steels, John Wiley \& Sons, USA, 2009.

[10]E.P. Papadakis, T.P. Lerch, Pulse superposition, pulse-echo overlap and related techniques, Handbook of elastic properties of solids, liquids and gases. 1 (2001).

[11]J. Capek, M. Cernik, N. Ganev, K. Trojan, J. Nemecek, K. Kolarik, Comparison of rolling texture of austenite and ferrite phases of duplex steel with single-phase austenitic and ferritic steel, IOP Conf. Ser.: Mater. Sci. Eng. 375.1 (2018) 012025. 